\title{
Legal hunting for conservation of highly threatened species: The case of African rhinos
}

\author{
Michael 't Sas-Rolfes ${ }^{1}$, Richard Emslie ${ }^{2}$, Keryn Adcock ${ }^{3}$, Michael Knight ${ }^{4}$ \\ ${ }^{1}$ School of Geography and the Environment and Oxford Martin School, University of \\ Oxford, United Kingdom of Great Britain and Northern Ireland \\ ${ }^{2}$ Ecoscot Consultancy Services, Hilton, South Africa \\ ${ }^{3}$ Wild Solutions, Hilton, South Africa \\ ${ }^{4}$ Centre for African Conservation Ecology, Zoology Department, Nelson Mandela \\ University, Port Elizabeth, South Africa
}

Corresponding author: tsas.rolfes@gmail.com

\begin{abstract}
Legal hunting of threatened species - and especially the recreational practice of 'trophy hunting' - is controversial with ethical objections being increasingly voiced. Less public attention has been paid to how hunting (even of threatened species) can be useful as a conservation tool, and likely outcomes if this was stopped. As case studies, we examine the regulated legal hunting of two African rhino species in South Africa and Namibia over the last half-century. Counter-intuitively, removing a small number of specific males can enhance population demography and genetic diversity, encourage range expansion, and generate meaningful socio-economic benefits to help fund effective conservation (facilitated by appropriate local institutional arrangements).
\end{abstract}

Legal hunting of African rhinos has been sustainable, with very small proportions of populations hunted each year, and greater numbers of both species today in these countries than when controlled recreational hunting began. Terminating this management option and significant funding source could have negative consequences at a time when rhinos are being increasingly viewed as liabilities and revenue generation for wildlife areas is being significantly impacted by COVID-19. Provided that there is appropriate governance conservation of certain highly threatened species can be supported by cautiously selective and limited legal hunting. 


\section{Introduction}

Cecil the lion's death invigorated challenges to both the social legitimacy and conservation contribution of legal recreational hunting of rare and threatened species ('t Sas-Rolfes, 2017). This prompted recent efforts to prevent hunting trophy imports to Western countries such as the United Kingdom and USA (Dickman et al., 2019). Aside from ethical arguments voiced against trophy hunting (Ghasemi, 2021) many in the popular and social media claim that it has caused population declines and that banning it would enhance conservation of currently legally hunted species. However, for at least some species the inverse may be true (IUCN, 2016).

Moral critics of recreational hunting, and especially the taking of trophies, tend to raise objections by appealing to deontological or virtue ethical arguments, which are mostly concerned with the nature of, or motivations for, specified actions (Nelson et al., 2016). However, if biodiversity conservation is considered an ethical and policy imperative, then pragmatic consequentialist arguments, which are concerned with the outcomes of actions, are also relevant (Johnson et al., 2019). The European Union Court of Justice recently affirmed that, consistent with the precautionary principle, environmental policy and laws pertaining to hunting should be informed by good science (Epstein et al., 2019). This in turn, implies evaluating the consequences of policy measures in a social-ecological context (Di Minin et al., 2021).

We document the extent and outcomes of regulated hunting of Africa's two rhino species in South Africa and Namibia over the last half-century as a dual case study. After outlining its history, the ecological and socio-economic arguments for it, and evident impacts on rhino conservation, we conclude with some remarks on policy implications for conservation in general.

\section{History of rhino hunting}

Historically, Africa's free-ranging populations of white rhinos (Ceratotherium simum) and black rhinos (Diceros bicornis) were substantially reduced through expansive agricultural development and uncontrolled hunting for sport, meat, and rhino horn. Black rhinos were reduced to low numbers in South Africa and Namibia, and by 1885 southern white rhinos (C.s.simum) had been reduced to a single population of only $\sim 20-50$ in what is today 
Hluhluwe-iMfolozi Park (HiP), South Africa. Under strict protection, numbers of both species recovered in both countries, following which carefully regulated legal hunting recommenced.

\section{White rhino}

The southern white rhino population in HiP grew steadily under protection from 1885 and by 1961 numbers had reached such high levels that concerns about potential 'overgrazing' and accelerated bush encroachment led to the start of a bold white rhino translocation and reintroduction programme (Player, 2013). Hundreds of rhinos were moved to numerous public and private reserves within South Africa (including Kruger National Park), and to seven former African range states, and zoos and safari parks around the world. Early founder groups were often markedly female-biased, creating an excess male problem in the original source population (see Supplementary Material: SM1a). The Natal Parks Board therefore sought to increase the number of areas willing to take more males by allowing private purchase of excess rhinos for a nominal fee and easing protective legislation to allow legal hunting in 1969. Recreational hunting of some of those animals under permit started in 1972 when the total wild population was estimated at $\sim 2,100$.

Initially a regular low-cost supply of excess rhinos from state areas led to excessive hunting on some private reserves (Buys, 1987). This changed when market-driven live rhino auctions were introduced in 1986, and new South African legislation in 1991 further secured private ownership of rhinos. Increased live sale prices resulted, encouraging a focus on breeding, and white rhino numbers on private land in the country have continued to grow since (Emslie et al. 2019). Sales of excess animals provided an additional source of funding for state conservation, and promoted growth of the private conservation sector, with some of it driven by hunting tourism. Namibia also implemented legislative changes to enable private landowners to benefit from wildlife on their land, including white rhinos, while maintaining permitting controls over hunting, which had commenced in 1982. The success of this model prompted the easing of international controls for South African white rhino hunting trophy exports in 1994.

From 2006, 'pseudo-hunting' of white rhino in South Africa to obtain horn for illegal sale into Asian markets temporarily became a problem (Milliken \& Shaw, 2012). The 
implementation of control measures by South Africa in 2012 brought this abuse under control (Emslie et al., 2019). To date the number of white rhino hunted has not been subject to any quotas, but apart from the peak pseudo-hunting period, high prices have generally ensured that only a limited number are hunted each year. The most recent South African white rhino biodiversity plan includes sustainable hunting as a key strategic component toward meeting its conservation target.

\section{Black Rhino}

Continental black rhino numbers declined sharply to around 2,360 in 1994/95. Subsequent protection and active use of translocations to enhance recovery saw numbers more than double across the continent, to an estimated 5,366-5,627 by 2017 (Emslie et al., 2019). South Africa and Namibia have both grown their black rhino numbers from a small base-from $\sim 110$ rhinos in South Africa in 1933, and 300 in Namibia in 1970. Range and numbers have increased since, with both countries now conserving similar numbers, jointly comprising $\sim 3,975(70.6 \%)$ of Africa's black rhinos in 2018 — up from only about 2.9\% ( 741) in 1973 .

An excess male problem (see following section) had also long been identified in some black rhino populations and confirmed by detailed population status reporting collated by the SADC Rhino Management Group (RMG) since 1989 (Adcock 2001). In response, in 2004, both South Africa and Namibia successfully applied for CITES quotas to export up to five black rhino trophies each per annum. Building on scientific recommendations (LeaderWilliams et al., 2005) the SADC RMG, in consultation with stakeholders, developed a black rhino hunting permit application approval system for use in South Africa. This was adopted and became part of the country's current black rhino biodiversity management plan. Its criteria were designed to ensure that only applications to hunt specific black rhino that further demographic and/or genetic conservation of breeding populations are approved. From 2019 South Africa's black rhino export quota changed, to $0.5 \%$ of the total population (automatically adjusting the maximum quota up or down in response to changes in rhino numbers). In Namibia, the Ministry of the Environment and Tourism makes all the decisions relating to how many and which black rhino are to be hunted, pursuant of its conservation goals. 


\section{Biological conservation aspects}

Rhino population performance is density dependent (e.g., Okita Ouma, 2004; SM1b) and all official rhino plans/strategies (national and continental) recommend keeping established populations at productive densities through removals. Regular removals from established populations can maintain productive densities in donor populations and provide founder rhinos that can be invested in new areas with the potential for enhanced growth (Adcock, 2019). The compounding effects of even small increases in growth rates can result in many more rhinos over time, increasing a species' ability to withstand poaching. Managing populations for growth also minimizes loss of genetic heterozygosity through genetic drift (Emslie \& Brooks, 1999). While most management removals involve live translocations, some rhinos have also been hunted in Namibia and South Africa.

Rhinos have on average a slightly (statistically significant) male-biased sex ratio at birth (53\% males for black rhinos-Adcock, 2001). Chance variation around this mean results in some populations having an even greater male bias. Rhino males are territorial and may fight to obtain or maintain territories. SADC RMG status reporting since 1989 has revealed that as black rhino densities have increased in some populations, deaths from fighting have often noticeably increased. Excluding translocation-related mortality, fighting has accounted for $40 \%$ of known-cause recorded natural black rhino deaths $(\mathrm{N}=660)$. Of these, where sex and age were known $(n=239 / 264), 70.7 \%$ were male $(35.1 \%$ adult males 7 years + and $36.8 \%$ calf and sub-adult males). However, a significant number of breeding adult females (13.8\%) and female calves and sub-adults (14.2\%) are also being caught up and killed in fights (SADC RMG data, Adcock, 2019).

Establishing new rhino populations is expensive and, where possible, a slightly skewed female biased founder group is desirable. However, this can negatively impact on the sex ratio of the donor populations if not corrected for by removing additional males.

This excess male problem cannot be solved by simply moving excess males to other populations:

- Reserves with female-biased populations can grow numbers faster and do not want more males. 
- Introducing excess males into existing populations carries large risks for the males themselves but also the resident breeding stock (Brett, 1998). Linklater et al. (2011) noted that restocking an area that already had black rhino had a higher mortality rate $(13.4 \%)$ compared with an initial introduction (7.9\%). Adult male-only introductions comprised only $8.2 \%$ of released individuals but $21.9 \%$ of introduction-related deaths.

- There are limited opportunities to place excess black rhino males into male-only populations. In 2014 there were 11 such populations established in South Africa and one in Namibia; but these were generally in small areas not suitable for breeding herds. Inter-male fighting losses in male-only sites do occur, but are not heightened, due to lack of females (Adcock, 2019).

Middle-aged to old black rhino males ( $>25$ years old) may be pushed out of their territories by younger dominant bulls into sub-optimal areas. Such animals are unlikely to breed again. (Adcock et al., 1998). Namibian authorities feared that leaving such marginalized animals in areas close to human settlements could lead to opportunistic poaching and stimulate further surges in illegal activity. Previous attempts to catch and reintroduce older black rhino bulls that were displaced from Etosha National Park were mostly unsuccessful, resulting in either fighting-related mortalities or the same rhinos being displaced again. Limited conservation funding could be spent more effectively elsewhere.

Managers need to limit inbreeding and maintain genetic diversity in populations - especially smaller ones. While some degree of inbreeding will be natural, if one or two dominant males have dominated the breeding for a significant period, their removal can enhance the genetic diversity and long-term viability of that population. Further detail on biological management of excess males is provided in SM1b. Karsten et al. (2011) found that this meta-population strategy appears to be delivering a genetically healthy population.

\section{Socio-economic aspects}

Rapid human population growth and associated economic pressures (especially prevalent in developing African countries) threaten wildlife through either unsustainable exploitation for subsistence and commercial purposes, or loss of wildlife habitats following land-use changes (IPBES, 2019). Rhinos are especially threatened by poaching to meet the persistent demand for their horns, leading to significant recurring financial obligations to cover essential 
security and management costs (Di Minin et al., 2022). Such costs vary by area. Items typically include infrastructure provision and maintenance (e.g., roads, fencing), staff expenses (salaries, accommodation, etc.), vehicles/aircraft, equipment (weapons, monitoring, communications, etc.), dog units, and, in some instances, veterinary services and supplementary feeding. The essential challenge for rhino conservators is to meet and contain these substantial costs, which have increased considerably with the increased poaching pressure over the last decade.

Contemporary African rhino conservators include government conservation agencies and, increasingly, private landowners (Emslie et al., 2019). In both South Africa and Namibia, white rhinos on private land are legally owned by the landowners; in South Africa some black rhinos are privately owned. The institutional arrangements in these countries include selective devolution of wildlife ownership and management authority, a model identified by Child (2019) as having performed best in terms of conserving large mammal populations both outside and within protected areas in Africa. Both countries also employ a conservation financing system that differs significantly from most other countries: being essentially decentralized, diversified, and supported by market mechanisms that channel direct monetary benefits from wildlife to relevant local levels rather than aggregating them centrally (where they are at greater risk of reallocation).

Two rhino conservation financing model variants exist in the two countries. South Africa's model is substantially market-oriented, whereas Namibia uses a hybrid model, treating the two species differently. The market-oriented model supplements rhino protection in state parks by enabling non-state landowners to benefit financially from activities such as photographic tourism, legal hunting, and live sales. This creates private incentives to protect and grow rhino populations on non-state land. State conservation agencies have also benefitted financially from live rhino sales to the private sector (Figure 1a). Figure $1 \mathrm{~b}$ illustrates the mechanism for financing black rhino conservation in Namibia. Proceeds from black rhino trophy hunts are channeled into a state-administered Game Products Trust Fund and earmarked for contributions to specific rhino monitoring and management activities and support for community conservancies.

Critiques of the socio-economic effects of trophy hunting suggest that its contributions to country-level GDP are small relative to non-hunting wildlife tourism, and that benefits from 
hunting may be inequitably distributed, entrenching social inequality (Ghasemi, 2021). Whereas distributional concerns apply to all forms of wildlife tourism (hunting and nonhunting), and socio-economic transformation remains a pressing priority in many developing countries, the former claim is misleading. National GDP contributions are a poor indicator in terms of both broader socio-economic relevance and appropriate scale of analysis. GDP metrics fail to consider essential ecosystems services and natural capital (Costanza et al., 1997). Nation states are an arbitrary level at which to make such assessments - more relevant are the global benefits of effective species conservation and ecosystem services provided by intact habitats, functionally populated with rhinos, and the more localized benefits that flow to specific rural landowners and communities, who are thereby incentivized to actively support conservation.

Arguments that contrast photographic with hunting tourism are misguided as these activities are mostly complementary rather than competing. Historically, hunting tourism has often acted as a pioneering developmental activity, providing the economic impetus to later establish photographic wildlife tourism operations. The hunting trophy fee and associated income generated (e.g., daily rates) per individual animal hunted is substantial —in at least one photographic tourism area where occasional high-value hunts still take place, the latter still recently funded the largest proportion of reserve expenditure (Cooney et al., 2017). Contemporary hunts typically take place in areas much less suited to photographic tourism and which sometimes form buffer zones or corridors to supplement protected areas. The current relatively small annual number of paying rhino hunters $(<100)$ generates far more conservation revenue per capita (with far lower environmental impact) than the far greater number of non-hunting tourists who can repeatedly observe a small sample of habituated animals in relatively confined areas (Shumba et al., 2021; Figure 2). A sensitivity analysis in Namibia demonstrates interdependence of the two activities and that the permanent loss of hunting tourism income would render most community conservancies economically unviable (Naidoo et al., 2016).

\section{Conservation impact of legal rhino hunting}

By helping address the problems of excess males, high population densities, and inbreeding, limited targeted rhino hunting can help advance demographic and genetic conservation goals. 
The generation of additional revenue also helps pay for and incentivize rhino conservation action.

Figure 3a shows the growth of southern white rhino numbers since hunting started and how in relative terms the number hunted has been very small. While there have been no negative impacts following black rhino hunting, as discussed above hunting of white rhino was temporarily problematic for two periods (over-hunting on private land in early years and later 'pseudo-hunting' as shown by Figure 3b). Actions taken resolved these issues and white rhino numbers still increased during both periods.

From the first hunt in 2005 until the end of 2018, a total of 47 black rhinos had been hunted in South Africa and 12 in Namibia. Total numbers of white rhinos hunted (1972-2018) are estimated at 2,538 (South Africa) and 61 (Namibia). Estimated inflation-adjusted 2021 US\$ values for trophy fee turnover for white and black rhino up to and including 2018 for these two countries exceed $\$ 154$ million and $\$ 18.5$ million, respectively, with trophy fee averages of $\$ 58,956$ (white) and $\$ 314,847$ (black), yielding a total average of $\sim \$ 8.2 \mathrm{~m}$ per year during recent years (see SM2 for detailed data). For context, these figures exclude additional income from daily rates, linked tourism activities, taxidermy, and various derivative economic benefits such as employment, and habitat and ecosystem service provision on marginal land areas (where the incremental impact of such funds is substantial).

Figures 4 and 5 show trends in numbers of southern white and black rhinos in the two major rhino hunting countries relative to rhino numbers in other African range states, reflecting key policy change dates. Overall numbers of both species have increased since legal hunting restarted (with an 11-fold increase in white rhino numbers in South Africa and Namibia up to their peak in 2012), which has clearly been sustainable. The real threat to rhino populations is poaching for horn, causing escalated protection costs and reduced local incentives to conserve rhinos and their habitats - and not legal hunting (Emslie et al., 2019). The 15\% decline of continental white rhino numbers after 2012 to end 2017 was primarily the result of increased poaching, especially in the Kruger National Park (where hunting is not permitted), rather than legal hunting (with 423 legally hunted rhinos compared with 6,087 recorded poached over the five years 2013-17). Legal hunting is very selective and almost entirely males whereas poachers frequently kill valuable breeding females, also causing calf loss. 


\section{Conclusion}

The African rhino case studies suggest that appropriately managed and regulated legal hunting (with trophy exports) can reinforce (rather than compromise) species and habitat conservation. This positive outcome is achieved through institutional arrangements that direct the flow of socio-economic benefits to locally relevant levels, thereby providing both 1) a source of finance for essential rhino security and management and 2) positive incentives for rural communities and private landowners to support conservation more generally. Similar results have been achieved for various other species in other contexts in southern Africa and elsewhere in the world (Cooney et al., 2017). Importantly, careful selection of animals to be hunted can ensure that small starting population sizes are not an impediment to the successful employment of this strategy. In the case of white rhinos, it helped enable their numbers and range to grow significantly.

Nowak et al. (2019) suggest that trophy hunting bans 'create opening for change'. In the case of African rhinos there is a high risk that such action now would result in negative socioeconomic consequences at both local and national levels (Parker et al., 2019) with concomitant adverse outcomes for rhino conservation. As Africa struggles with declining sources of conservation funding in the wake of COVID-19 (Lindsey et al., 2020) policy makers must trade off such risks against the application of evolving ethical standards. Perhaps counter-intuitively, it is for relatively rare but actively managed species such as African rhinos that such complete hunting bans may carry the highest risk of an adverse conservation outcome.

Mindful of the increasing animosity towards trophy hunting, we suggest that regulation of hunting and trophy trade of threatened species should be evaluated on a case-by-case basis, given that there remain clear instances, such as for African rhinos, where legal hunting contributes positively toward achieving specified conservation goals.

\section{Acknowledgements and data}

We thank: David Cook, Pierre du Preez, and Coenraad Vermaak for insights relating to historical events; Piet Beytell and Fillemon Iifo of the Namibian Ministry of the Environment, Forestry and Tourism, and Mpho Tjiane of the South African Department of Forestry, Fisheries and the Environment, for assistance with data provision. MtR gratefully 
acknowledges funding from Oppenheimer Generations Research and Conservation. Information on data sources is provided in SM3.

\section{References}

't Sas-Rolfes, M. (2017). African wildlife conservation and the evolution of hunting institutions. Environmental Research Letters, 12(11), 115007.

Adcock, K., Hansen, H. B., \& Lindemann, H. (1998). Lessons from the introduced black rhino population in Pilanesberg National Park. Pachyderm, 26, 40-51.

Adcock, K. (2001). RMG Black rhino Carrying Capacity Model version 1.0: User's Guide (Evaluation Draft). SADC Regional Programme for Rhino Conservation. https://fliphtml5.com/cpmu/eesr/basic

Adcock, K. (Ed.). (2019). Status and Management of Black Rhino in Namibia, South Africa Zimbabwe, Botswana, Zambia, Malawi and eSwatini to December 2018. Includes SADC RMG data 1989 to 2018 (Confidential data submitted to the Southern African Development Community Rhino Management Group, with reporting by South Africa, Namibia, Zimbabwe, Botswana, Zambia, Malawi and Swaziland/eSwatini). SADC Rhino Management Group.

Brett, R. (1998). Mortality factors and breeding performance of translocated black rhinos in Kenya: 1984-1995. Pachyderm, 26, 69-82.

Buys D. (1987). A summary of the introduction of white rhino onto private land in the Republic of South Africa: Report for Rhino and Elephant Foundation. http://www.rhinoresourcecenter.com/pdf_files/129/1291956323.pdf

Child, B. (2019). Sustainable Governance of Wildlife and Community-Based Natural Resource Management (1 edition). Routledge.

Cooney, R., Freese, C., Dublin, H., Roe, D., Mallon, D., Knight, M., Emslie, R., Pani, M., Booth, V., Mahoney, S., \& Buyanaa, C. (2017). The baby and the bathwater: Trophy hunting, conservation and rural livelihoods. Unasylva, 68(249), 3-16.

Costanza, R., d'Arge, R., de Groot, R., Farber, S., Grasso, M., Hannon, B., Limburg, K., Naeem, S., O’Neill, R. V., Paruelo, J., Raskin, R. G., Sutton, P., \& van den Belt, M. (1997). The value of the world's ecosystem services and natural capital. Nature, 387(6630), 253-260. https://doi.org/10.1038/387253a0 
Di Minin, E., Clements, H. S., Correia, R. A., Cortés-Capano, G., Fink, C., Haukka, A., Hausmann, A., Kulkarni, R., \& Bradshaw, C. J. A. (2021). Consequences of recreational hunting for biodiversity conservation and livelihoods. One Earth, 4(2), 238-253. https://doi.org/10.1016/j.oneear.2021.01.014

Di Minin, E., ’t Sas-Rolfes, M., Selier, J., Louis, M., \& Bradshaw, C. J. A. (2022).

Dismantling the poachernomics of the illegal wildlife trade. Biological Conservation, 265, 109418. https://doi.org/10.1016/j.biocon.2021.109418

Dickman, A., Cooney, R., Johnson, P. J., Louis, M. P., Roe, D., \& Signatories, 128. (2019). Trophy hunting bans imperil biodiversity. Science, 365(6456), 874-874. https://doi.org/10.1126/science.aaz0735

Emslie, R., \& Brooks, M. (1999). African rhino: Status survey and conservation action plan. IUCN. https://portals.iucn.org/library/node/7613

Emslie, R. H., Milliken, T., Talukdar, B., Adcock, K., \& Knight, M. H. (2019). African and Asian rhinoceroses-Status, conservation and trade: A report from the IUCN Species Survival Commission (IUCN/SSC) African and Asian Rhino Specialist Groups and TRAFFIC to the CITES Secretariat pursuant to Resolution Conf. 9.14 (Rev. CoP17), CoP18 Doc. 83.1 Annex 2. CITES Secretariat. https://cites.org/sites/default/files/eng/cop/18/doc/E-CoP18-083-01.pdf

Epstein, Y., López-Bao, J. V., Trouwborst, A., \& Chapron, G. (2019). EU Court: Science must justify future hunting. Science, 366(6468), 961.

https://doi.org/10.1126/science.aaz8424

Ghasemi, B. (2021). Trophy hunting and conservation: Do the major ethical theories converge in opposition to trophy hunting? People and Nature, 3(1), 77-87. https://doi.org/10.1002/pan3.10160

IPBES. (2019). Global assessment report on biodiversity and ecosystem services of the Intergovernmental Science-Policy Platform on Biodiversity and Ecosystem Services. (E. S. Brondizio, J. Settele, S. Díaz, \& H. T. Ngo, Eds.). IPBES secretariat. https://doi.org/10.5281/zenodo.3553579

IUCN. (2016). Informing decisions on trophy hunting: A Briefing Paper for European Union Decision-makers regarding potential plans for restriction of imports of hunting trophies. IUCN. https://www.iucn.org/sites/dev/files/iucn_sept_briefing_paper_informingdecisionstrophyhunting.pdf

Johnson, P. J., Adams, V. M., Armstrong, D. P., Baker, S. E., Biggs, D., Boitani, L., Cotterill, A., Dale, E., O’Donnell, H., Douglas, D. J. T., Droge, E., Ewen, J. G., Feber, R. E., 
Genovesi, P., Hambler, C., Harmsen, B. J., Harrington, L. A., Hinks, A., Hughes, J., ... Dickman, A. (2019). Consequences Matter: Compassion in Conservation Means Caring for Individuals, Populations and Species. Animals, 9(12), 1115.

https://doi.org/10.3390/ani9121115

Karsten, M., Vuuren, B. J. van, Goodman, P., \& Barnaud, A. (2011). The history and management of black rhino in KwaZulu-Natal: A population genetic approach to assess the past and guide the future. Animal Conservation, 14(4), 363-370.

https://doi.org/10.1111/j.1469-1795.2011.00443.x

Leader-Williams, N., Milledge, S., Adcock, K., Brooks, M., Conway, A., Knight, M., Mainka, S., Martin, E. B., \& Teferi, T. (2005). Trophy Hunting of Black Rhino Diceros bicornis: Proposals to Ensure Its Future Sustainability. Journal of International Wildlife Law \& Policy, 8(1), 1-11. https://doi.org/10.1080/13880290590913705

Lindsey, P., Allan, J., Brehony, P., Dickman, A., Robson, A., Begg, C., Bhammar, H., Blanken, L., Breuer, T., Fitzgerald, K., Flyman, M., Gandiwa, P., Giva, N., Kaelo, D., Nampindo, S., Nyambe, N., Steiner, K., Parker, A., Roe, D., ... Tyrrell, P. (2020). Conserving Africa's wildlife and wildlands through the COVID-19 crisis and beyond. Nature Ecology \& Evolution, 1-11. https://doi.org/10.1038/s41559-020-1275-6 Linklater, W. L., Adcock, K., Preez, P. du, Swaisgood, R. R., Law, P. R., Knight, M. H., Gedir, J. V., \& Kerley, G. I. H. (2011). Guidelines for large herbivore translocation simplified: Black rhinoceros case study. Journal of Applied Ecology, 48(2), 493-502. https://doi.org/10.1111/j.1365-2664.2011.01960.x

Milliken, T., \& Shaw, J. (2012). The South Africa-Viet Nam Rhino Horn Trade Nexus: A Deadly Combination of Institutional Lapses, Corrupt Wildlife Industry Professionals and Asian Crime Syndicates. http://www.traffic.org/species- reports/traffic species mammals66.pdf.

Naidoo, R., Weaver, L. C., Diggle, R. W., Matongo, G., Stuart-Hill, G., \& Thouless, C. (2016). Complementary benefits of tourism and hunting to communal conservancies in Namibia. Conservation Biology, 30(3), 628-638. https://doi.org/10.1111/cobi.12643 Nelson, M. P., Bruskotter, J. T., Vucetich, J. A., \& Chapron, G. (2016). Emotions and the Ethics of Consequence in Conservation Decisions: Lessons from Cecil the Lion. Conservation Letters, 9(4), 302-306. https://doi.org/10.1111/conl.12232

Nowak, K., Lee, P. C., Marino, J., Mkono, M., Mumby, H., Dobson, A., Harvey, R., Lindsay, K., Lusseau, D., Sillero-Zubiri, C., \& Signatories, 71. (2019). Trophy hunting: Bans 
create opening for change. Science, 366(6464), 434-435.

https://doi.org/10.1126/science.aaz4135

Okita-Ouma, B. (2004). Population performance of black rhinoceros (Diceros bicornis michaeli) in six Kenyan rhino sanctuaries. Dissertation submitted for the degree of Master of Science in Conservation Biology, University of Kent.

Parker, K., Vos, A. D., Clements, H. S., Biggs, D., \& Biggs, R. (2020). Impacts of a trophy hunting ban on private land conservation in South African biodiversity hotspots. Conservation Science and Practice, 2(7), e214. https://doi.org/10.1111/csp2.214

Player, I. (2013). The White Rhino Saga. Jonathan Ball.

Shumba, T., De Vos, A., Biggs, R., Esler, K. J., \& Clements, H. S. (2021). The influence of biophysical and socio-economic factors on the effectiveness of private land conservation areas in preventing natural land cover loss across South Africa. Global Ecology and Conservation, 28, e01670. https://doi.org/10.1016/j.gecco.2021.e01670 


\section{Article figures}

\section{Figure 1}

a

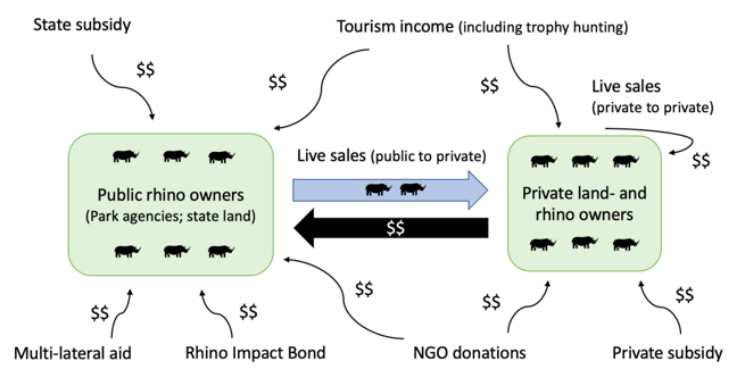

b

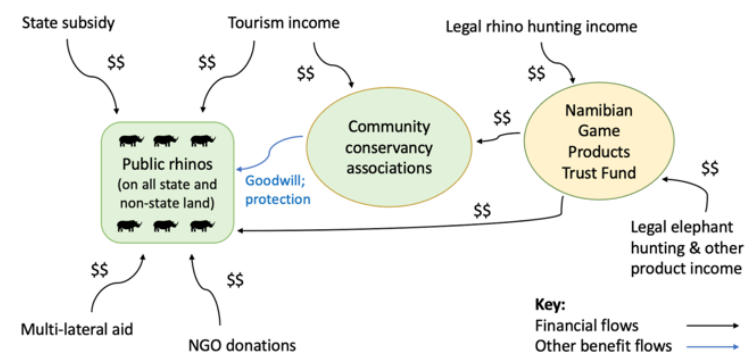

Financing models for rhino conservation: a) for South Africa and white rhinos in Namibia, and b) for black rhinos in Namibia 


\section{Figure 2}

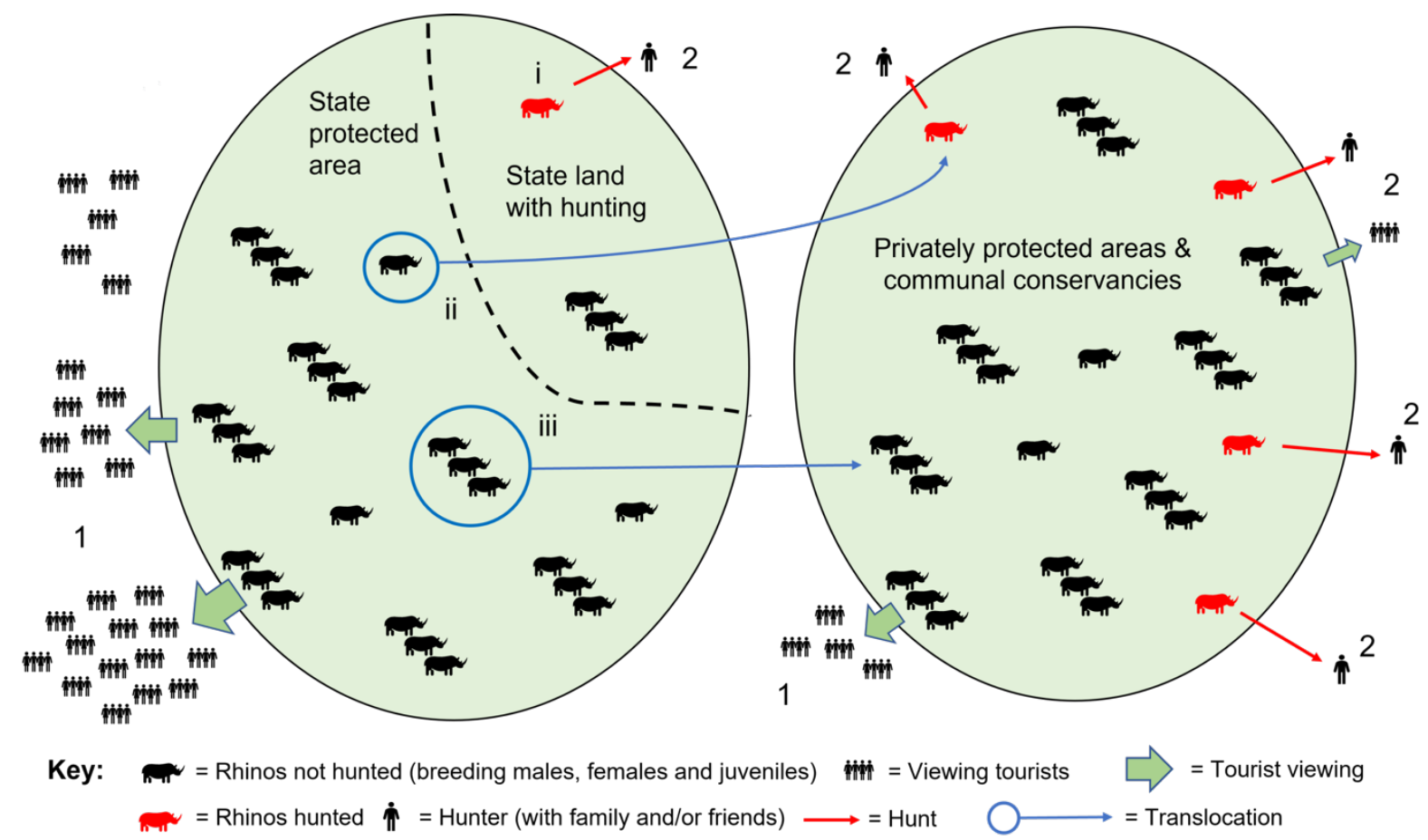

Rhino use on public and private lands, showing relative contributions of 1) numerous nonhunting tourist and 2) few legal hunting tourists. Rhinos move to private and hunting areas through i) natural dispersal, ii) translocation of excess males and iii) translocation of breeding herds. Hunts support additional range to that supported by non-hunting tourists alone and translocations provide financial support to reserves selling surplus rhinos. 


\section{Figure 3}

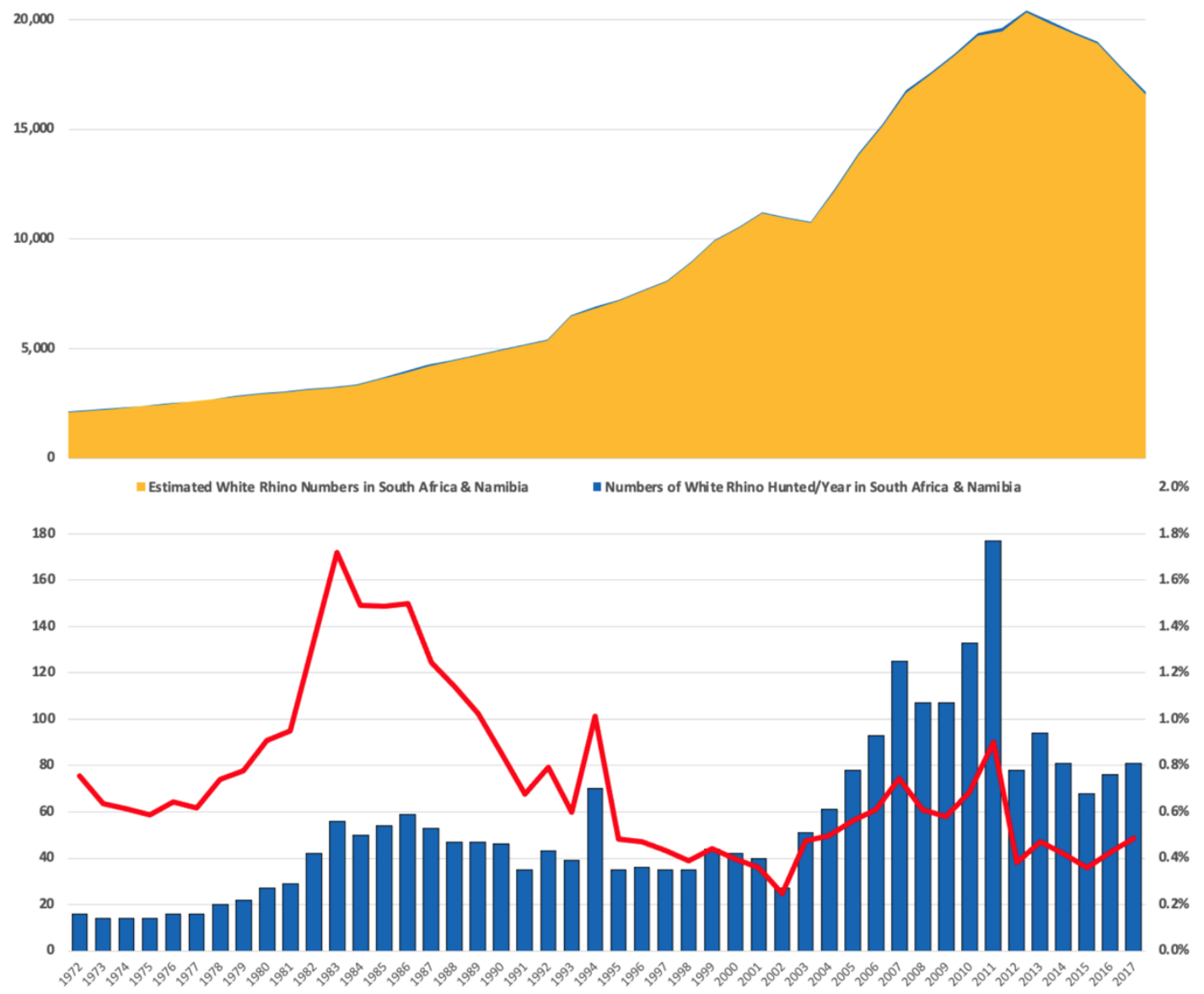

Numbers of White Rhino Hunted/Year in South Africa \& Namibia — $\quad$ of White Rhino Population in South Africa and Namibia Hunted/Yea

Above (a): Estimated numbers of live white rhinos in South Africa and Namibia (in yellow) and numbers legally hunted in these countries (blue).

Below (b): Absolute numbers of white rhino legally hunted (blue, left Y-axis) compared with relative $\%$ of population hunted (red, right Y-axis) 


\section{Figure 4}

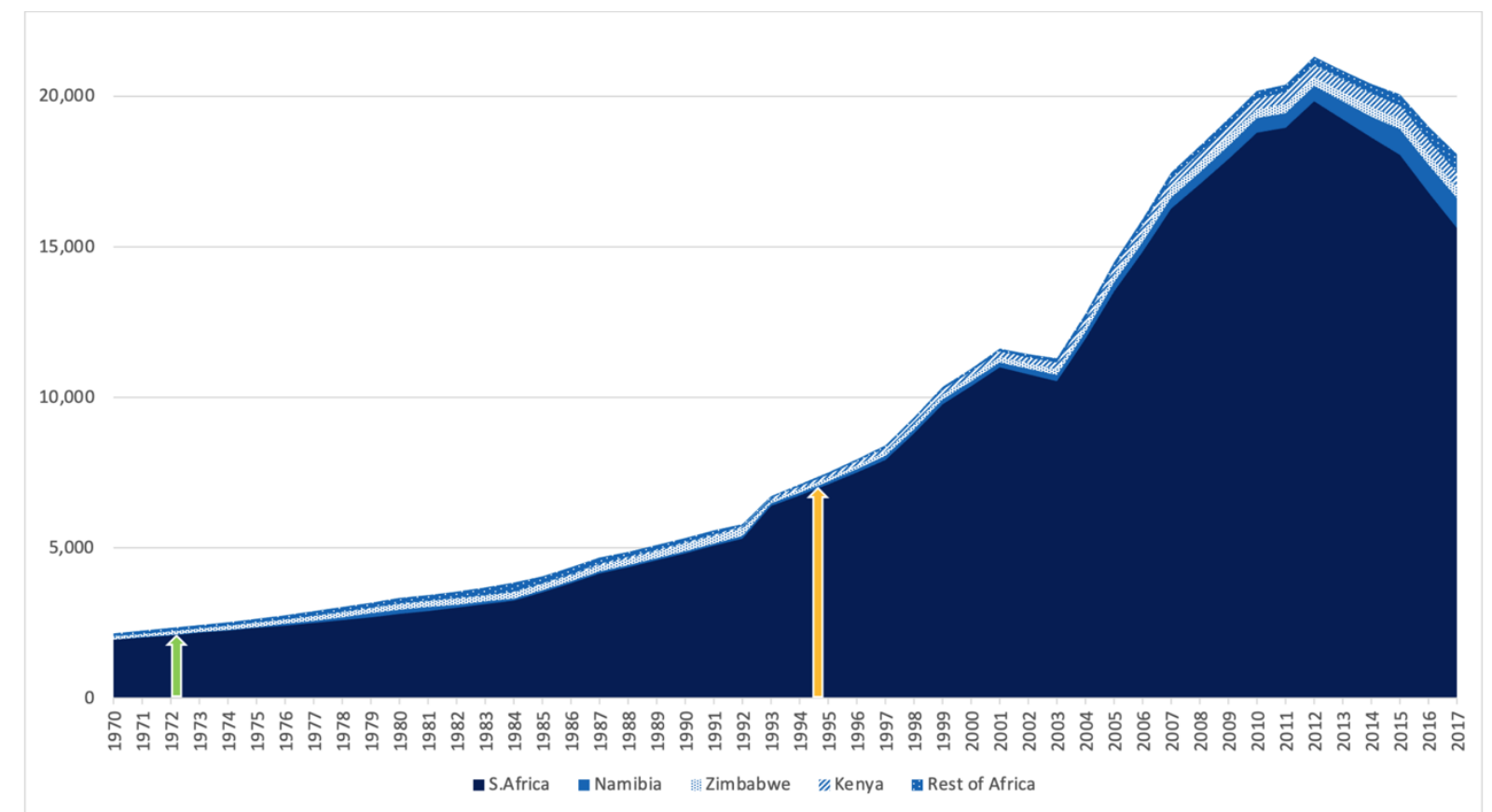

Total numbers of southern white rhinos by range state, with green arrow indicating commencement of legal hunting in South Africa, and yellow arrow indicating date of eased restrictions on South African trophy exports 


\section{Figure 5}

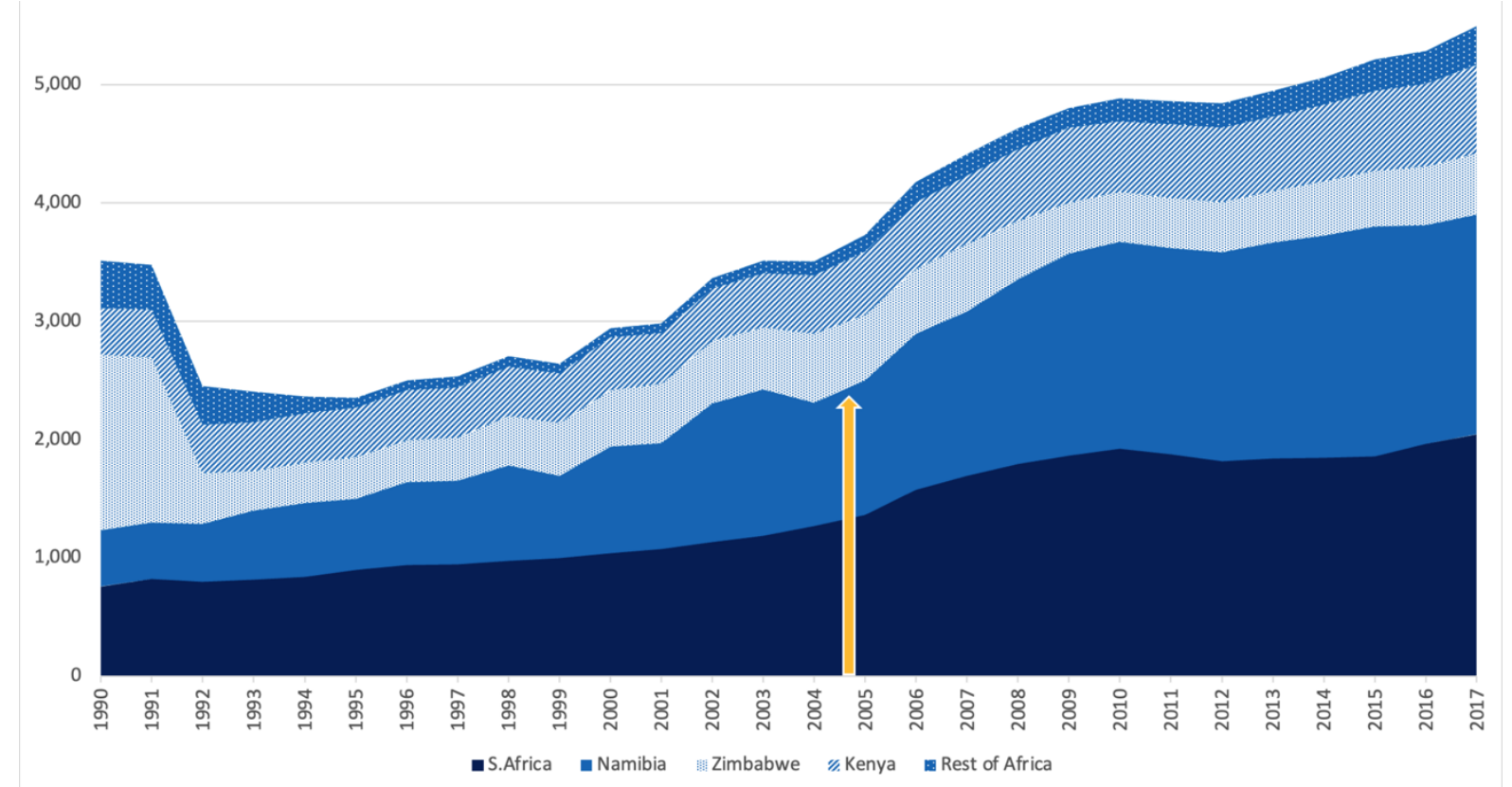

Total numbers of black rhinos by range state, before and after commencement of legal hunting, with yellow arrow indicating date of international approval of quotas for limited South African and Namibian hunts and trophy exports 


\section{Supplementary Material}

\section{Detailed information on 'excess male' problem}

\section{1a Excess males from Natal Parks Board southern white rhino reintroductions}

The southern white rhino translocation and reintroduction programme, 'Operation Rhino' commenced in what was then Umfolozi Game Reserve in 1961, from what at the time was the only remaining population of southern white rhino in the world. This was done to both reduce densities and increase range. By March 1972 almost a thousand white rhino had been moved to numerous public and private reserves within South Africa (including Kruger National Park), to seven former African range states, and zoos and safari parks around the world. Early founder groups for the rest of Africa and World were often markedly femalebiased, averaging four females for every three males n=526, Jan 1961-Mar 1972 (data from Player, 2013), creating an excess male problem at source. For example, $64 \%$ and $68 \%$ of early white rhino translocations to, respectively, Whipsnade in the UK and San Diego Zoo in the USA, were female. This practice persists: $63 \%$ of a founder white rhino group moved to Rwanda in 2021 was also female. This skewing of donor population sex ratio was dealt with at the time by supplying Kruger NP with a $57.1 \%$ male-biased founder groups in early years (data up to March 1972 in Player, 2013), and changing Natal's Provincial legislation to allow legal hunting in 1969 in an attempt to encourage more local private reserves to take more males. In contrast to the rest of South Africa, where slightly more females (52.7\% of 708 known sex) were moved onto private land, up to $1987,76.8 \%$ of the 418 of known sex white rhinos moved to private land within Natal over this period were male (based on data in Buys, 1987).

\section{1b Biological management of excess males}

In both African rhino species, adult males seek to become locally dominant and to hold territories. These are areas which have little overlap with other dominant males, and which are defended against other males which are or seek to be dominant. Males - usually younger males (but also other dominant males passing through another's territory to reach water) — that behave subordinately can be tolerated in a dominant male's territory, but are not much tolerated if females in oestrus are present. Females also have home ranges but these are not defended and overlap with other females ranges and male territories.

A given land area can thus only fit a limited number of male territories. This is influenced by the carrying capacity of the vegetation and the layout of the landscape features like water and inaccessible terrain. A problem with black rhinos is that when tensions among the males increases and there is more fighting, some females and their calves can also get caught up in it and injured or killed.

Excluding deaths that occurred post-release (and may therefore have been a direct result of translocations); fighting accounted for $40 \%$ of known-cause recorded natural black rhino deaths $(\mathrm{N}=660)$ Of these, where sex and age were known $(n=239 / 264), 70.7 \%$ were male $(35.1 \%$ adult males 7 years + and $36.8 \%$ calf and subadult males). However, a significant number of breeding adult females (13.8\%) and female calves and sub-adults (14.2\%) are also being caught up and killed in fights (SADC-RMG data 1989-2018: Adcock, 2019).

The conditions for increased fighting arise more often when:

a) More male than female calves get born over a period, and these males grow up to subadult or adulthood, becoming targets of male aggression. Data from both white and black rhino (and even the Asian greater one-horned rhino), across many sites of widely varying land area and management history, show that on average there is a 53-54\% birth sex skew toward males.

b) The general rhino population density becomes high with respect to the area's carrying capacity.

c) Live removals take more females than males from a site. 
Note that c) is usually only done when a new site requires a favourable breeding sex ratio, or has limited space for adult males. Usually the donor site will try re-balance by removing excess males to a site which needs a male for some reason, or to a male-only population, or to a site which can hunt the excess male if the donor site does not allow hunting; alternatively, the donor site may hunt one or more of the excess males itself.

In addition to a slightly male-biased average $53-54 \%$ sex ratio at birth, in the same way that tossing an unbiased coin ten times won't always give you exactly five heads, by chance some populations can also end up with even more markedly male skewed populations or male biased cohorts of youngsters. Aside from the risks of introducing males into areas with established populations, populations with more favourable female biased populations usually don't want any more males as they can breed up their numbers faster with more females. Opportunities for male only populations are also limited and they are usually small. This is because available suitable larger areas of protected habitat are prioritised for establishing new breeding populations.

Following recognition of declines in breeding performance in a number of conservatively harvested black rhino populations in South Africa and Kenya, increased attention was paid to improving biological management. In 2001, a SADC Rhino Management Group Biological Management Workshop reviewed relevant scientific principles and case studies and recommended that established populations be managed for growth, thus promoting the use of set \% harvesting (Emslie, 2001; Goodman, 2001; Emslie \& Du Toit, 2006; Balfour et al., 2019). Most rhino populations today occur in fenced reserves (preventing natural dispersal) and as rhino population performance is density dependent (Adcock, 2019; Emslie, 2001; Goodman, 2001; 2019; Goodman et al., 2019; Greaver et al., 2013), removals are needed to maintain population productivity. There is strong empirical evidence that regular removals from established populations (including excess males) maintains population growth rates in donor populations (Goodman et al., 2018; Goodman, 2019; Adcock 2019). The corollary is, that in the absence of removals, densities will increase to a point where rhino population growth rates slow considerably and may even turn negative.

Provided that removals are less than the reproductive potential of rhinos (their $r_{\max }$ ), the improved breeding performance of remaining rhinos in harvested populations in effect replaces the rhinos removed (Goodman et al., 2019; Adcock 2019). Therefore, hunting of $x$ male rhinos is not a simple subtraction that reduces overall rhino numbers by $x$. This is because, in practice, removed animals get replaced by enhanced population growth and if sex ratios are favourably altered in the process, population $\%$ growth rates and overall numbers may even increase. With regular removals (e.g., of 5\% per year), experience has matched the theory, with densities in an established populations adjusting to a level that can support that level of offtake, and the underlying breeding rate of such populations will be similar to the removal rate (Goodman et al., 2019; Adcock, 2019). This is because density reductions in established populations free up food reserves for remaining animals. This is especially important for breeding females, which need to be on a high nutritional plane to successfully raise calves and then recover sufficient condition rapidly after the demands of lactation to have another calf soon after their last (and hence maintain shorter inter-calving intevals and higher population growth rates).

In addition to maintaining productive densities, removals provide founder rhinos that can be invested in new areas with the potential for enhanced growth - thus increasing both numbers and range. Strategically it is also better to have more "baskets" of rhinos. Thanks to compounding, increased metapopulation growth rates can result in many more rhinos, increasing a species' ability to withstand poaching.

Managing for rapid population growth also minimizes loss of genetic heterozygosity through genetic drift (Brooks \& Emslie, 1999). In some populations one or two males may have dominated the breeding for 
many years and in such cases their removal (through translocation or hunting) may boost genetic diversity in those populations.

For the above reasons, all official rhino plans/strategies recommend keeping established populations at productive densities through regular removals (Emslie, 2001; Emslie \& du Toit, 2006; Balfour et al., 2019).

The removal of some excess males in skewed populations through hunting is therefore undertaken by management with the aims of reducing fighting, contributing to improving markedly male-biased sex ratios (where these occur) and maintaining productive densities (to the benefit of remaining breeding females and breeding rates).

In one interesting case, a dominant black rhino bull was hunted in South Africa after being suspected of being infertile. In this case monitoring revealed that females in his area had not calved for a few years and a motivation to hunt this bull was accepted. The adult females in the area subsequently began calving again after after this bull had been hunted suggesting he had indeed been infertile. Thus, in this unusual case, the removal of a single bull ended up boosting rhino numbers.

\section{$\underline{\text { References: }}$}

Adcock, K. (Ed.). (2019). Status and Management of Black Rhino in Namibia, South Africa Zimbabwe, Botswana, Zambia, Malawi and eSwatini to December 2018. Includes SADC RMG data 1989 to 2018 (Confidential data submitted to the Southern African Development Community Rhino Management Group, with reporting by South Africa, Namibia, Zimbabwe, Botswana, Zambia, Malawi and Swaziland/eSwatini). SADC Rhino Management Group.

Balfour, D., Shaw, J., Banasiak, N., le Roex, N., Rusch, U., \& Emslie, R.H. (2019). Concise best practice guidelines for the biological management of African Rhino. WWF_SA 123pp. http://www.rhinoresourcecenter.com/pdf_files/157/1577109509.pdf

Buys, D. (1987). A summary of the introduction of white rhino onto private land in the Republic of South Africa: Report for Rhino and Elephant Foundation. http://www.rhinoresourcecenter.com/pdf files/129/1291956323.pdf

Emslie, R.H. (2001). Current Recommended Strategy For Maximising Growth. In: R Emslie (ed) Proceedings of a SADC Rhino Management Group (RMG) workshop on biological management to meet continental and national black rhino conservation targets. SADC Regional Programme for Rhino Conservation, Harare. Proceedings of this workshop including this paper and a related paper by RF du Toit. http://www.rhinoresourcecenter.com/ref_files/1175860813.pdf

Emslie, R., \& Brooks, M. (1999). African rhino: Status survey and conservation action plan. IUCN. https://portals.iucn.org/library/node/7613

Emslie, R.H., \& du Toit, R.F. (2006). Summary of Guidelines for Ensuring Optimal Biologocal Management - Chapter 4 in Guidelines for Implementing SADC Rhino Conservation Strategies du Toit RF (ed) SADC Regional Programme for Rhino Conservation, Harare, Zimbabwe. http://www.rhinoresourcecenter.com/pdf_files/119/1190402258.pdf.

Goodman, P.S. (2001). Black rhino harvesting strategies to improve and maintain productivity and minimise risk. In: R. Emslie (ed) Proceedings of a SADC Rhino Management Group (RMG) workshop on biological management to meet continental and national black rhino conservation targets. SADC Regional Programme for Rhino Conservation, Harare. Proceedings of this workshop are downloadable at http://www.rhinoresourcecenter.com/ref_files/1175860813.pdf 
Goodman, P.S., Conway, A.J., Flamand, J., \& Clinning, G. (2018). Harvesting black rhino populations in KwaZulu-Natal to improve their status - results and lessons learned. Presentation at 2018 Rhino Science Meeting held at Dinokeng Game Reserve.

Goodman, P.S. (2019). Live Harvesting Black Rhinos - Presentation at the $13^{\text {th }}$ IUCN SSC AfRSG meeting, $7^{\text {th }}$ February 2019, Gross Barmen, Namibia.

Greaver, C, Ferreira, S., \& Slotow, R. (2013). Density-dependent regulation of the critically endangered black rhinoceros population in Ithala Game Reserve, South Africa Austral Ecology Dec 2013.

Player, I. (2013). The White Rhino Saga. Jonathan Ball.

\section{Annual hunting data}

The following tables provide the estimated number of rhinos hunted by species by country by year together with average nominal trophy prices and estimated adjusted US\$2021 Present Values for annual turnover of trophy fees.

In many cases these average trophy fees will not include additional daily rate charges usually levied for a minimum of 7-10 days for a rhino hunt. Additional charges for non-hunting companions of the hunter are also often added. Even as far back as 1994 these additional daily-rate fees could be as much as $\$ 7,500$ per rhino hunt for a hunter and one companion $(\$ 14,000$ today). Thus the actual hunt turnover including these daily rate fees could be considerably higher than shown. Some trophy fees are quoted including these daily rates while for others the rates are quoted separately. The total present value trophy fee turnover for both species totalled US\$172.63 million. Including probable additional daily rate fees for many hunts, total turnover might therefore have exceeded US\$ 0.2 billion. Annual 2021 Present Value of hunting fee turnover (averaged over the 5 years 2014-18) amounts to $\$ 6.96 \mathrm{~m} / \mathrm{yr}$ for White Rhinos, $\$ 1.23 \mathrm{~m} / \mathrm{yr}$ for Black Rhinos and totals $\$ 8.19 \mathrm{~m} / \mathrm{yr}$ for both species.

\begin{tabular}{|c|c|c|c|c|c|c|c|c|c|c|c|c|c|c|c|c|c|}
\hline \multirow{3}{*}{$\begin{array}{l}\text { Year } \\
2005\end{array}$} & \multicolumn{3}{|c|}{ Number of Black Rhinos Hunted } & \multicolumn{4}{|c|}{ Nominal Trophy Fee/Rhino US\$ } & & \multicolumn{3}{|c|}{ Present 2021 US\$ Trophy } & \multicolumn{6}{|c|}{ 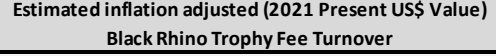 } \\
\hline & \multirow{2}{*}{$\frac{\text { S. Africa }}{3}$} & \multirow[t]{2}{*}{ Namibia } & \multirow{2}{*}{ Total } & \multicolumn{2}{|c|}{ S.Africa } & \multicolumn{2}{|r|}{ Namibia } & & S.Africa & & Namibia & \multicolumn{2}{|r|}{ S. Africa } & \multicolumn{2}{|r|}{ Namibia } & \multicolumn{2}{|r|}{ Total } \\
\hline & & & & $\$$ & 216,455 & & & $\$$ & 306,837 & & & $\$$ & 920,511 & & & $\$$ & 920,511 \\
\hline 2006 & 5 & & 5 & $\$$ & 220,000 & & & $\$$ & 302,158 & & & $\$$ & $1,510,788$ & & & $\$$ & $1,510,788$ \\
\hline 2007 & 4 & & 4 & $\$$ & 230,000 & & & $\$$ & 306,976 & & & $\$$ & $1,227,903$ & & & $\$$ & $1,227,903$ \\
\hline 2008 & 3 & & 3 & $\$$ & 230,000 & & & $\$$ & 295,650 & & & $\$$ & 886,951 & & & $\$$ & 886,951 \\
\hline 2009 & 2 & 1 & 3 & $\$$ & 232,500 & $\$$ & 144,928 & $\$$ & 300,029 & $\$$ & 187,022 & $\$$ & 600,058 & $\$$ & 187,022 & $\$$ & 787,080 \\
\hline 2010 & 4 & 1 & 5 & $\$$ & 235,000 & $\$$ & 198,939 & $\$$ & 298,027 & $\$$ & 252,294 & $\$$ & $1,192,107$ & $\$$ & 252,294 & $\$$ & $1,444,401$ \\
\hline 2011 & 4 & 0 & 4 & $\$$ & 267,500 & & & $\$$ & 329,154 & & & $\$$ & $1,316,617$ & & & $\$$ & $1,316,617$ \\
\hline 2012 & 5 & 1 & 6 & $\$$ & 300,000 & $\$$ & 237,154 & $\$$ & 361,749 & $\$$ & 285,967 & $\$$ & $1,808,743$ & $\$$ & 285,967 & $\$$ & $2,094,710$ \\
\hline 2013 & 4 & 3 & 7 & $\$$ & 294,934 & $\$$ & 233,149 & $\$$ & 350,532 & $\$$ & 277,100 & $\$$ & $1,402,128$ & $\$$ & 831,300 & $\$$ & $2,233,428$ \\
\hline 2014 & 5 & 0 & 5 & $\$$ & 320,496 & & & $\$$ & 374,856 & & & $\$$ & $1,874,279$ & & & $\$$ & $1,874,279$ \\
\hline 2015 & 1 & 1 & 2 & $\$$ & 346,054 & $\$$ & 350,000 & $\$$ & 404,035 & $\$$ & 408,642 & $\$$ & 404,035 & $\$$ & 408,642 & $\$$ & 812,677 \\
\hline 2016 & 2 & 2 & 4 & $\$$ & 300,067 & $\$$ & 87,524 & $\$$ & 346,070 & $\$$ & 100,942 & $\$$ & 692,141 & $\$$ & 201,885 & $\$$ & 894,026 \\
\hline 2017 & 3 & 2 & 5 & $\$$ & 312,051 & $\$$ & 231,485 & $\$$ & 352,522 & $\$$ & 261,507 & $\$$ & $1,057,565$ & $\$$ & 523,014 & $\$$ & $1,580,579$ \\
\hline 2018 & 2 & 1 & 3 & $\$$ & 300,299 & $\$$ & 300,000 & $\$$ & 330,779 & $\$$ & 330,449 & $\$$ & 661,557 & $\$$ & 330,449 & $\$$ & 992,006 \\
\hline Totals & 47 & 12 & 59 & & & & & & & & & $\$$ & $15,555,383$ & $\$$ & $3,020,573$ & $\$$ & $18,575,956$ \\
\hline Avg $n / Y^{*}$ & 3.4 & 1.2 & 4.2 & & & & & & & & rage 2021 P & $\overline{N T}$ & hy Fee/Black Rh & hino & & $\$$ & 314,847 \\
\hline
\end{tabular}

Table S1 - Summary of black rhino hunting information for South Africa and Namibia from 2005-2018 (see Section 3 for further details) 


\begin{tabular}{|c|c|c|c|c|c|c|c|c|c|c|c|c|}
\hline \multirow{3}{*}{$\begin{array}{l}\text { Year } \\
1972\end{array}$} & \multicolumn{3}{|c|}{ Number of White Rhinos Hunted } & \multirow{2}{*}{$\begin{array}{l}\text { Nominal Trophy } \\
\text { Fee/Rhino US\$ } \\
\text { S. Africa }\end{array}$} & \multirow{2}{*}{\multicolumn{2}{|c|}{$\begin{array}{c}\text { Present } 2021 \\
\text { US\$ Trophy } \\
\text { Fee/Rhino US\$ } \\
\text { S. Africa }\end{array}$}} & \multicolumn{6}{|c|}{$\begin{array}{c}\text { Estimated inflation adjusted (2021 Present US\$ Value) } \\
\text { White Rhino Trophy Fee Turnover }\end{array}$} \\
\hline & \multirow{2}{*}{$\frac{\text { S. Africa }}{16}$} & \multirow[t]{2}{*}{ Namibia } & \multirow{2}{*}{$\frac{\text { Total }}{16}$} & & & & & S. Africa & & Namibia & & Total \\
\hline & & & & 10,403 & $\$$ & 68,868 & $\$$ & $1,101,888$ & & & $\$$ & $1,101,888$ \\
\hline 1973 & 14 & & 14 & 9,925 & $\$$ & 61,985 & $\$$ & 867,790 & & & $\$$ & 867,790 \\
\hline 1974 & 14 & & 14 & 9,469 & $\$$ & 53,123 & $\$$ & 743,722 & & & $\$$ & 743,722 \\
\hline 1975 & 14 & & 14 & 9,034 & $\$$ & 46,361 & $\$$ & 649,054 & & & $\$$ & 649,054 \\
\hline 1976 & 16 & & 16 & 8,619 & $\$$ & 41,955 & $\$$ & 671,280 & & & $\$$ & 671,280 \\
\hline 1977 & 16 & & 16 & 8,223 & $\$$ & 37,543 & $\$$ & 600,688 & & & $\$$ & 600,688 \\
\hline 1978 & 20 & & 20 & 7,845 & $\$$ & 33,292 & $\$$ & 665,840 & & & $\$$ & 665,840 \\
\hline 1979 & 22 & & 22 & 7,485 & $\$$ & 28,477 & $\$$ & 626,494 & & & $\$$ & 626,494 \\
\hline 1980 & 27 & & 27 & 7,141 & $\$$ & 23,997 & $\$$ & 647,919 & & & $\$$ & 647,919 \\
\hline 1981 & 29 & & 29 & 6,813 & $\$$ & 20,784 & $\$$ & 602,736 & & & $\$$ & 602,736 \\
\hline 1982 & 41 & 1 & 42 & 6,500 & $\$$ & 18,628 & $\$$ & 763,748 & $\$$ & 18,628 & $\$$ & 782,376 \\
\hline 1983 & 56 & 0 & 56 & 6,354 & $\$$ & 17,674 & $\$$ & 989,744 & $\$$ & - & $\$$ & 989,744 \\
\hline 1984 & 50 & 0 & 50 & 5,680 & $\$$ & 15,101 & $\$$ & 755,050 & $\$$ & - & $\$$ & 755,050 \\
\hline 1985 & 53 & 1 & 54 & 8,264 & $\$$ & 21,287 & $\$$ & $1,128,211$ & $\$$ & 21,287 & $\$$ & $1,149,498$ \\
\hline 1986 & 55 & 4 & 59 & 8,660 & $\$$ & 21,881 & $\$$ & $1,203,455$ & $\$$ & 87,524 & $\$$ & $1,290,979$ \\
\hline 1987 & 52 & 1 & 53 & 10,357 & $\$$ & 25,207 & $\$$ & $1,310,764$ & $\$$ & 25,207 & $\$$ & $1,335,971$ \\
\hline 1988 & 51 & 0 & 51 & 17,500 & $\$$ & 40,936 & $\$$ & $2,087,736$ & $\$$ & - & $\$$ & $2,087,736$ \\
\hline 1989 & 47 & 1 & 48 & 36,669 & $\$$ & 81,734 & $\$$ & $3,841,498$ & $\$$ & 81,734 & $\$$ & $3,923,232$ \\
\hline 1990 & 42 & 0 & 42 & 31,108 & $\$$ & 65,794 & $\$$ & $2,763,348$ & $\$$ & - & $\$$ & $2,763,348$ \\
\hline 1991 & 34 & 1 & 35 & 30,500 & $\$$ & 61,936 & $\$$ & $2,105,824$ & $\$$ & 61,936 & $\$$ & $2,167,760$ \\
\hline 1992 & 42 & 1 & 43 & 28,500 & $\$$ & 56,152 & $\$$ & $2,358,384$ & $\$$ & 56,152 & $\$$ & $2,414,536$ \\
\hline 1993 & 39 & 0 & 39 & 22,500 & $\$$ & 43,049 & $\$$ & $1,678,911$ & $\$$ & - & $\$$ & $1,678,911$ \\
\hline 1994 & 69 & 1 & 70 & 15,656 & $\$$ & 29,195 & $\$$ & $2,014,455$ & $\$$ & 29,195 & $\$$ & $2,043,650$ \\
\hline 1995 & 35 & 0 & 35 & 26,113 & $\$$ & 47,361 & $\$$ & $1,657,635$ & $\$$ & - & $\$$ & $1,657,635$ \\
\hline 1996 & 35 & 1 & 36 & 26,113 & $\$$ & 46,098 & $\$$ & $1,613,430$ & $\$$ & 46,098 & $\$$ & $1,659,528$ \\
\hline 1997 & 35 & 0 & 35 & 26,113 & $\$$ & 45,018 & $\$$ & $1,575,630$ & $\$$ & - & $\$$ & $1,575,630$ \\
\hline 1998 & 35 & 0 & 35 & 25,000 & $\$$ & 42,436 & $\$$ & $1,485,260$ & $\$$ & - & $\$$ & $1,485,260$ \\
\hline 1999 & 43 & 1 & 44 & 25,000 & $\$$ & 41,479 & $\$$ & $1,783,597$ & $\$$ & 41,479 & $\$$ & $1,825,076$ \\
\hline 2000 & 40 & 2 & 42 & 30,254 & $\$$ & 48,612 & $\$$ & $1,944,480$ & $\$$ & 97,224 & $\$$ & $2,041,704$ \\
\hline 2001 & 40 & 0 & 40 & 31,000 & $\$$ & 48,401 & $\$$ & $1,936,040$ & $\$$ & - & $\$$ & $1,936,040$ \\
\hline 2002 & 25 & 2 & 27 & 30,015 & $\$$ & 46,209 & $\$$ & $1,155,225$ & $\$$ & 92,418 & $\$$ & $1,247,643$ \\
\hline 2003 & 50 & 1 & 51 & 29,030 & $\$$ & 43,677 & $\$$ & $2,183,850$ & $\$$ & 43,677 & $\$$ & $2,227,527$ \\
\hline 2004 & 60 & 1 & 61 & 26,575 & $\$$ & 38,922 & $\$$ & $2,335,320$ & $\$$ & 38,922 & $\$$ & $2,374,242$ \\
\hline 2005 & 78 & 0 & 78 & 29,305 & $\$$ & 41,542 & $\$$ & $3,240,276$ & $\$$ & - & $\$$ & $3,240,276$ \\
\hline 2006 & 92 & 1 & 93 & 29,785 & $\$$ & 40,908 & $\$$ & $3,763,536$ & $\$$ & 40,908 & $\$$ & $3,804,444$ \\
\hline 2007 & 124 & 1 & 125 & 32,000 & $\$$ & 42,710 & $\$$ & $5,296,040$ & $\$$ & 42,710 & $\$$ & $5,338,750$ \\
\hline 2008 & 103 & 4 & 107 & 54,479 & $\$$ & 70,029 & $\$$ & $7,212,987$ & $\$$ & 280,116 & $\$$ & $7,493,103$ \\
\hline 2009 & 107 & 0 & 107 & 43,705 & $\$$ & 56,399 & $\$$ & $6,034,693$ & $\$$ & - & $\$$ & $6,034,693$ \\
\hline 2010 & 131 & 2 & 133 & 59,699 & $\$$ & 75,710 & $\$$ & $9,918,010$ & $\$$ & 151,420 & $\$$ & $10,069,430$ \\
\hline 2011 & 173 & 6 & 179 & 84,870 & $\$$ & 104,431 & $\$$ & $18,066,563$ & $\$$ & 626,586 & $\$$ & $18,693,149$ \\
\hline 2012 & 73 & 3 & 76 & 85,000 & $\$$ & 102,496 & $\$$ & $7,482,208$ & $\$$ & 307,488 & $\$$ & $7,789,696$ \\
\hline 2013 & 91 & 4 & 95 & 72,750 & $\$$ & 86,464 & $\$$ & $7,868,224$ & $\$$ & 345,856 & $\$$ & $8,214,080$ \\
\hline 2014 & 79 & 4 & 83 & 79,056 & $\$$ & 92,464 & $\$$ & $7,304,656$ & $\$$ & 369,856 & $\$$ & $7,674,512$ \\
\hline 2015 & 64 & 3 & 67 & 79,592 & $\$$ & 92,928 & $\$$ & $5,947,392$ & $\$$ & 278,784 & $\$$ & $6,226,176$ \\
\hline 2016 & 74 & 11 & 85 & 74,017 & $\$$ & 85,364 & $\$$ & $6,316,936$ & $\$$ & 939,004 & $\$$ & $7,255,940$ \\
\hline 2017 & 76 & 8 & 84 & 83,195 & $\$$ & 93,985 & $\$$ & $7,142,860$ & $\$$ & 751,880 & $\$$ & $7,894,740$ \\
\hline 2018 & 56 & 9 & 65 & 80,080 & $\$$ & 88,208 & $\$$ & $4,939,648$ & $\$$ & 793,872 & $\$$ & $5,733,520$ \\
\hline Totals & 2,538 & 75 & 2,613 & & & & $\$$ & $148,383,035$ & $\$$ & $5,669,961$ & $\$$ & $154,052,996$ \\
\hline Avg $n / Y r^{*}$ & 54.0 & 2.0 & 55.6 & & $\mathrm{Av}$ & $2021 \mathrm{PV}$ & Trop & y Fee/White Rhi & ino & & $\$$ & 58,956 \\
\hline
\end{tabular}

Table S2 - Summary of white rhino hunting information for South Africa and Namibia from 1972-2018 (see Section 3 for further details) 


\section{Sources of data and information}

\section{Acknowledgements}

Before detailing the sources of the data used in this paper, the authors would like to acknowledge and thank the many people in range states, and especially the official country representatives, who over the decades have contributed information on rhino numbers to the IUCN Species Survival Commission's African Rhino Specialist Group (AfRSG) and Southern African Development Community Rhino Management Group (SADC RMG). Over the last thirty years, this has allowed regular updating of rhino population and poaching data and facilitated IUCN Red Listing updates and the mandated reporting to the Convention on International Trade in Endangered Species of Fauna and Flora (CITES) Conferences of the Parties by IUCN, on trends in rhino numbers, hunting, and poaching. The Rhino Resource Centre is a great source of many references with old historical estimates, and Kees Rookmaaker is thanked for his foresight and effort in creating and maintaining this invaluable source of rhino information.

The authors are especially grateful to Pierre du Preez, Piet Beytell, and Fillemon Iifo in Namibia, Thea Carroll and Mpho Tjiane in South Africa, and David Cumming in Zimbabwe for providing information on hunting in their countries over the years. For the earlier years we have drawn heavily on data compiled by Daan Buys as part of the first survey of white rhino on private land in South Africa. Information collected in 1994 and supplied by Richard Emslie as part of an international cost:benefit Study of rhino conservation funded by the Worldwide Fund for Nature (WWF) and Wildlife Conservation Society (WCS) was also helpful. The Endangered Wildlife Trust (EWT) and TRAFFIC are also thanked for providing access to data and CITES permits at that time of cost:benefit study data collection. A number of major hunters and outfitters at the time were consulted as part of this process, as were provincial conservation agency representatives (including the then Bophutatswana Parks Board, aka 'Bop Parks'and its subsidiary company Kgama Safaris) and the Professional Hunters Association of South Africa (PHASA). Those who contributed information at the time included Gary Davies, the late Jo Brooks, the late Ashish Boadasing, Keryn Adcock, Jules Turnbull-Kemp, Lesly Dalton, Keith Meiklejohn, and Duncan Paul. Subsequently the late Ian Player, Coenraad Vermaak, and David Cook provided useful historical information and comment.

African Range states are also thanked for providing the AfRSG with regular poaching statistics.

\section{Estimated Rhino Numbers}

Estimated rhino numbers from 1973 used in this paper and shown in Figures 3, 4, and 5 were taken from a continental database of estimated rhino numbers per year by country and subspecies/genetic management cluster. This database was specifically set up by Richard Emslie as then Coordinator of IUCN's Red List Authority on behalf of the IUCN Species Survival Commission's African Rhino Specialist Group (AfRSG) to collate historical numbers used as the basis for assessing population trends over the last 1,2, or 3 generations as part of the latest IUCN African Rhino Red Listing assessment revisions (Emslie, 2020).

\section{Source of estimated numbers post 1992}

Since 1992, data on African black and white rhino numbers have been collected and compiled by the AfRSG every one to three years (in 1992, 1993, 1995, 1997, 1999, 2001, 2003, 2005, 2007, 2010, 2012, 2015, and 2017, with complete black rhino estimates also available for 2018). Annual black rhino numbers for many major (but not all) rhino range states have also been collected and compiled by Keryn Adcock for the SADC Rhino Management Group through its regular status reporting (covering the period 1989-2018). These were used by AfRSG and IUCN's African Rhino Red List authority to improve continental estimates for years between AfRSG continental surveys. Eleven surveys of the status of white rhinos on private land in South Africa from 1987 to 2018 have also contributed to estimated numbers. 
Regular updates of continental rhino numbers broken down by range state and subspecies/genetic management cluster are published in AfRSG Chair reports in the journal Pachyderm, and as part of mandated joint IUCN/TRAFFIC rhino reports to CITES Conferences of the Parties (e.g., Emslie et al. 2019). Individual population breakdowns continue to be kept confidential at the request of some range states. To always use the best estimates possible, past estimates have sometimes been adjusted slightly up or down in the light of updated information or improved data analyses that has revised estimates.

\section{Source of estimated numbers 1980-1991}

Before the formation of the AfRSG, its predecessor, the IUCN SSC African Elephant and Rhino Specialist Group, compiled continental estimates for each country for 1980, 1984, and 1987 (Western \& Vigne, 1985; Cumming et al., 1990).

\section{Source of estimated numbers pre-1980}

Klingel's (1979) survey of African rhinoceroses for IUCN also provided estimates for many populations across Africa in the late 1970s. Numerous other data sources, listed in the IUCN African Rhino Red List Assessment supplementary document (Emslie, 2020), were also used to derive the best possible estimates for the period 1973-1979 (and also before this). Emslie \& Brooks (1999) also provided some historical numbers.

\section{Interpolation of numbers between years}

Population estimates were not available for every country every year. Estimates for missing years were interpolated by applying constant annual growth/decline rates that match up with available starting and end period estimates. ${ }^{1}$

\section{Uncertainty around point estimates of numbers}

Population measurement error is often a large source of uncertainty for many species, but this is less of a problem for African rhinos, with many populations being monitored using individual identification-based methods. Very large rhino populations in larger protected areas and some other smaller, less-wellmonitored sites, plus incomplete reporting on some white rhino populations on private land in South Africa, are the main sources of uncertainty in rhino numbers.

Several unrounded point estimates are given in the paper, prefaced by $\sim$. These must be interpreted as having a degree of uncertainty around them. For example, as was reported to CITES CoP18, Emslie et al. 's (2019) bootstrapped estimates of $90 \%$ confidence levels around the 2017 continental point estimate of 18,067 white rhino were 17,212 to 18,915 ; and were 5366 to 5627 around the black rhino estimate of $5495 .^{2}$ Importantly, trends in estimated numbers of both species over time shown in Figures 3, 4, and 5 are of a much greater magnitude that the degree of uncertainty around individual point estimates for any given year (as indicated by above bootstrapped confidence levels).

\footnotetext{
${ }^{1}$ For example, supposing one only had estimates for a population of 211 in year 0 and 249 in year 3 (i.e., there were no estimates for years 1 and 2). This represents a total increase over the three years of $18.00948 \%$. Raising 1.1800948 to the power of (1/number of years) gives 1.0567 or an average annual compounded increase of $5.67 \%$. Applying this annual growth rate gives rounded interpolated estimates for year 1 of 223, and 236 for year 2. Applying this annual growth rate for a third year returns 249 - the same as the recorded population estimate for year 3 .

${ }^{2}$ The bootstrapping was based on actual calculated confidence levels or best estimates of likely estimate precision for each population. What this means statistically, is that if we were to repeatedly estimate rhino numbers many times, then on average in about 9 out of 10 cases (assuming estimation is unbiased) the true number of rhinos would be expected to fall within our estimated $90 \%$ confidence levels.
} 


\section{Source of further information}

For further information on numbers and data sources used in African Rhino Red Listing (which are also used in this paper) see section titled "Population estimates used for assessing changes over one, two and three generations" in Supplementary Document for most recent IUCN African Rhino Red List Assessments: https://www.iucnredlist.org/species/pdf/152728945/attachment

Figure SI below is reprinted from the African Rhino Red Listing Supplementary document (Emslie 2020) and shows the estimated continental trends in rhino numbers since 1973 by subspecies/genetic management cluster.

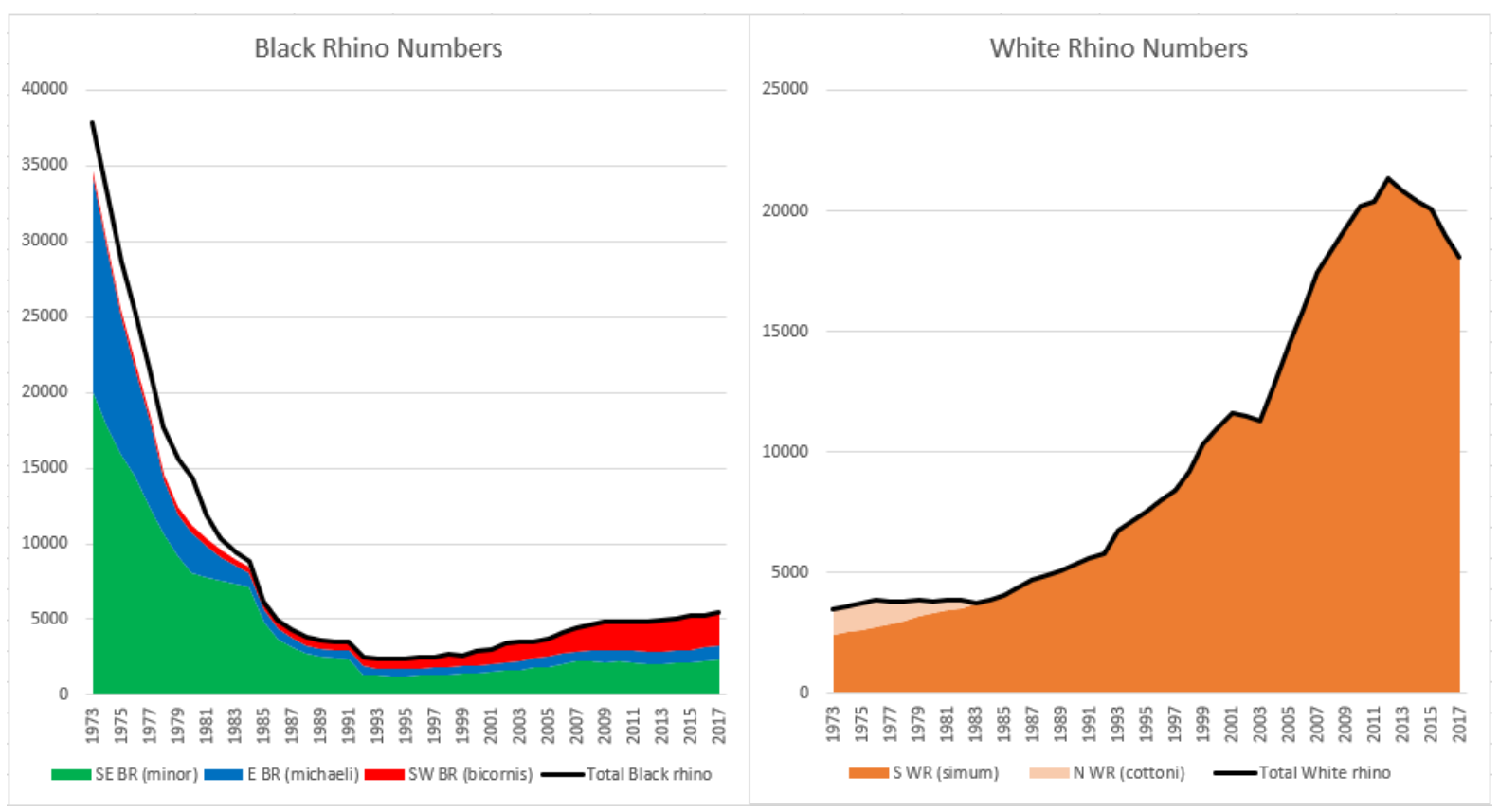

Figure SI: Graph of estimated black and white rhino numbers by subspecies/genetic management cluster from the African rhino historical numbers database developed used to assess changes in numbers over three generations (44 years) under Criteria A2 and A4.

\section{References:}

Cumming, D.H.M, Du Toit, R.F., \& Stuart S.N. (1990). African Elephants and Rhinos - Status Survey and Conservation Action Plan. IUCN SSC African Elephant and Rhino Specialist Group. IUCN, Gland, Switzerland.

Emslie, R. (2020). Red List, supplementary information: African Rhinos (Ceratotherium simum and Diceros bicornis, including the subspecies). In: IUCN 2020. IUCN Red List of Threatened Species. $<$ www.iucnredlist.org $>$ : pp. 1-54.

Emslie, R., \& Brooks, M. (1999). African rhino: Status survey and conservation action plan. IUCN. https://portals.iucn.org/library/node/7613

Klingel, H. (1979). Survey of African Rhinoceroses. Report to IUCN SSC African Elephant and Rhino Specialist Group.

Western, D., \& Vigne, L. (1985). The Status of Rhinos in Africa. Pachyderm 4: 5-6. 


\section{Estimated numbers hunted and trophy fees}

A database of the numbers of rhino hunted has been built up over time by the authors, and has been updated in recent years with data provided by South African and Namibian authorities. Data has also been reported to the Parties to the Convention on International Trade in Endangered Species of Wild Fauna and Flora (CITES) in joint IUCN/TRAFFIC rhino reports (e.g., Emslie et al., 2019). These reports form part of the CITES Secretariat's reporting on rhinos at CITES Conferences of the Parties (CoP's).

Much of the early compilation of South African hunting numbers came from an earlier analysis by Adcock \& Emslie (1994) published in the proceedings of a symposium, "Rhinos as Game Ranch Animals".

Allocation of estimated total white rhino numbers hunted in the early years (only given as a total for 19681987 in Adcock \& Emslie 1994) were based on a survey of white rhino on private land by Daan Buys (1987). Estimates have since been improved for this paper by estimating numbers hunted broken down by year based largely on the raw data in an Appendix ("Known numbers of rhinos shot on properties") in Buys (1987). In 54 out of the 59 properties listed by Buys as having rhinos hunted (up to and including 1987), numbers hunted were provided.

However, Buys indicated that for the other six properties listed the real figures were not known, and he estimated numbers hunted as the difference between deliveries and numbers in 1987 (not taking births into account). Recorded deliveries (suspected hunted) were listed by Buys as starting on one of these properties in 1968, and this is probably why 1968 has been quoted as having been the date of the restart of hunting in the more modern era. However, it has come to our attention from official sources previously involved with conservation in the Province of Natal (where the first hunt took place) that the first hunt was in 1972; hence, for our estimation purposes we have taken the period of hunting on this one property as starting in 1972, not 1968 when the first rhinos were delivered. This also matches up with dates of provincial legal changes to allow hunting. These six properties accounted for 55\% (241) of the estimated 436 white rhino numbers that Buys estimated had been hunted in South Africa (not including Bophuthatswana).

While a detailed breakdown of numbers hunted per year were given for some properties by Buys, for others he just listed the total number hunted over specified time periods. As an example, a total of five were listed as hunted in one property over a seven year period, 1981-87. For our estimation of numbers hunted, these five animals were allocated equally over the whole seven year period (i.e., 0.714 year). Estimated numbers hunted for the 59 listed properties (from 1972-1987) were then summed by year and rounded to the nearest rhino. The total was then checked to ensure that the annual total summed to the total 436 that Buys had estimated and recorded.

Almost all (97.9\%) of these animals were hunted on private land, with only nine recorded hunted on provincial reserves (not including Bop Parks' reserves where an additional 59 were hunted over the same period and which were were not included in Buys's estimates).

As part of data collection for an international study of cost:benefits of different rhino conservation approaches in Africa and Asia in the early 1990s, Richard Emslie interviewed a number of hunting outfitters and representatives of several provincial conservation agencies, and further analysed South African CITES export permits over a limited period (database and analysis based on cross referencing individual permits) and data supplied by TRAFFIC SA. A copy of the detailed typed notes submitted to the lead researcher of this study was consulted and used by Richard Emslie to derive updated best estimates of the numbers hunted for 1991-94 in South Africa (excluding Bophutatswana). Richard also obtained a full record of the number of white rhino hunted per year in the former semi-autonomous territory of Bophutatswana from 1982-1994 (not included in the 436 hunted recorded by Buys).

At the time, no data had been found by Richard Emslie for South Africa (excluding Bophutatswana) for the three years 1988-90. The average number hunted in South Africa (excluding Bophutatswana) for the three previous and three subsequent years (i.e., 1985-87 and 1991-93) gives an estimated total of 115 
rhinos over the three year period. This is the same number estimated for this period by Hall-Martin et al. (2009). Instead of allocating the 115 equally over the three years, the breakdown of numbers by HallMartin et al. for these three years (i.e., 42, 39, 34) was used and added to numbers hunted by Bop Parks to give total South African estimates for 1988-90.

Data on numbers hunted between 1994 and 2004 were provided to the authors by the former South African Department of Environmental Affairs (DEA), currently the Department of Fisheries, Forestry, and the Environment (DFFE). SA data from 2004 is as reported in Emslie et al. (2019); these data were derived from information provided by DEA/DFFE, Milliken \& Shaw (2012), and Hall-Martin et al. (2009).

Hall-Martin et al. (2009) also estimated numbers hunted/year from 1972-2008 per year (in their Table 2.4). Their estimates were based on information from PHASA, CITES permit reports from DEA, and interviews with players in the industry. Their paper indicated they drew heavily on CITES permit reports, but noted that at the time hunting stats could be improved upon as these numbers different from hunts reported by provinces.

In collecting and compiling information and data for the cost:benefit study in 1994, Richard Emslie found a number of issues that made it difficult to use CITES database data provided to him by TRAFFIC to estimate numbers of rhino hunted. This is because CITES permits are focused on recording legal export of specified rhino parts, (rather than being developed with the primary objective of accurately determining the number of individual animals hunted). For example one animal hunted can have multiple permits issued for different parts (skull, skin, feet), there may be delays caused by taxidermy meaning that exports of some or all body parts were not in the same year as hunts, permits sometimes expired (e.g., due to taxidermy delays or if hunts were delayed) requiring permits to be issued again (with a risk of double counting), and some permits issued end up not being used (e.g., if a hunt was cancelled). The issue is further complicated by different parts of the same animal on occasion being sent out at different times (requiring multiple permits for one animal), In some cases it was also not clear if both or just one horn was on the permit. Taxidermists were also sometimes in different provinces to where hunts took place requiring additional permits, further complicating analysis.

The executive officer of PHASA at the time was interviewed as part of the cost:benefit study data collection. Notes at that time indicated that PHASA did not have good records of white rhino hunting.

For almost a quarter (24.3\%) of the years over their reporting period Hall-Martin et al. (2009) used an average estimate of 32 for the nine years they did not have estimates. Some of their earlier estimates were also questionable with, for example, numbers they estimate hunted over one three year period jumping wildly from 40 to 1 and then back up to 44 . According to one hunter involved at that time (Coenraad Vernaak, personal communication) such extreme fluctuations in numbers hunted did not happen. The averaged Hall-Martin et al. (2009) estimates also do not reflect the gradual build up in numbers hunted over time that is indicated by the Buys 1987 report data table.

For these reasons we we have not used the Hall-Martin et al. (2009) figures (with the exception of 198890 discussed above, and for some other years where our estimates matched those in Hall-Martin et al. exactly). While our and Hall-Martin et al.'s (2018) estimates for some individual years varied, the estimated totals hunted over the period 1972-2008 were very similar (1,506 in this paper, 1,536 in HallMartin et al., 2009).

As Hall-Martin et al. (2009) did, the need for better record keeping of hunts was also noted by Richard Emslie in 1994 at the time of data collection for the cost:benefit study. In more recent years DEA/DFFE have created a national hunting database that records many details about rhino hunts and permits issued.

While these figures cannot be taken as being a completely accurate reflection of the exact numbers of white rhino hunted each year they are likely to provide a reasonable representation of the trends over time 
in South Africa. The figures used (and detailed in Section 2, above), represent our best estimates given the information available from a wide variety of sources.

Black rhino hunting only started more recently in South Africa and details of hunts have been provided by DEA/DFFE.

The first recorded trophy fee we have is for the first hunt in 1972 which was ZAR8,000 (South African rands). The 1972 ZAR value was converted to give a nominal US\$ value using average ZAR:US\$ annual exchange rates obtained from the World Bank database. ${ }^{3}$ There is a gap in knowledge regarding trophy fees for the more limited numbers of white rhino hunted in the early years from 1973-1981, with the next documented trophy fee prices being compiled by Hall-Martin et al. (2009). Their values for 1982-1989 were used. As hunting prices came to be quoted primarily in US\$ values, and more of the average US\$ prices ended in 0 it was decided to use Hall-Martin et al's quoted US\$ prices for 1982-89 (rather than their average rand prices). US\$ values were then interpolated to estimate missing average prices in US\$ for 1973-1981. An imputed price from Milliken and Shaw (2012) was used for 1990. Estimates for 1991-94 average trophy fees were obtained from Richard Emslie's detailed data notes provided to an international rhino cost:benefit study. Prices for 1991-93 were taken as the average of the average Kgama Safari's trophy fee and average Natal trophy fee for each year obtained from Kgama Safaris and the then Natal Parks Board. More individual prices were available from a range of ouftitters in 1994 and the estimatated average trophy fee for this year was an average of 11 trophy fees documented in the cost:benefit study data. The declines in price over the period 1991-94 were due to uncertainty brought about by the first independence election in South Africa in 1994. Average trophy fees for 1995-2009 were taken from Milliken \& Shaw (2012) while more recent data was provided by DEA/DFFE.

Historical Namibian black rhino hunting data (numbers hunted, and black rhino trophy fees) were provided to the authors by the Namibian Ministry for Environment, Forestry, and Tourism (MET).

Earlier estimates of numbers of white rhinos hunted in Namibia prior to 2011 were derived from an analysis of CITES import and export database reports for hunting trophies. From 2011-2017 numbers hunted were as provided to the IUCN SSC AfRSG by the Namibian MET (and as documented in Emslie et al. 2019, except for a correction to reallocate two hunts to the year before). The number hunted in Namibia in 2018 was provided to the authors by the Namibian MET. Average trophy fees for white rhino hunted in Namibia were not available. However, as the white rhinos hunted in Namibia were on private land, and the industry is competitive, average South African prices per year were used to estimate annual turnover.

Black rhino trophy fee estimates for 2005, 2009, and 2011 were not available for South Africa nor for 2012 for Namibia. The South African 2005 nominal black rhino trophy fee was estimated as $98.39 \%$ of the 2006 fee (assuming the same \% change as white rhino trophy fees from 2005-2006). South African 2009 and 2011 estimates of average black rhino hunt prices were simply estimated as averages of values for the years on either side. While South African black rhino trophy fees from 2006-2011 were available in US\$, prices were only available in South African rands from 2012 onwards. Average rand prices for 2012-2018 were converted to US\$ using the World Bank exchange rates.

No trophy fee was available for the single black rhino hunted in 2012 in Namibia. This was estimated by applying the same ratio of the 2012/2013 average black rhino fees recorded in South Africa to the recorded 2013 Namibian average trophy fee.

Thus, for both South Africa and Namibia, we have been able to compile a good record of estimated numbers of both species hunted per year since legal hunting restarted, and further can provide estimates of annual and total earnings from trophy fees. Average nominal trophy fees were inflation adjusted to convert them to present value (as of December 2021). Present value average prices were then multiplied by

\footnotetext{
${ }^{3}$ https://data.worldbank.org/indicator/PA.NUS.FCRF?locations=ZA
} 
numbers hunted to derive present value turnovers. Official US Bureau of Labour Statistics' Consumer Price Index data were used by Officialdata.org to derive values for what \$1 in 1972 was worth for every year up to and including $2021 .{ }^{4}$ These data showed that $\$ 1$ in 1972 is equivalent to a purchasing power today (as of December 2021) of $\$ 6.62$, indicating that annual inflation has averaged 3.93\% per year over the period. Multipliers used to convert nominal US\$ trophy values to present late 2021 values were simply derived by dividing $\$ 6.62$ by what $\$ 1$ in 1972 would be worth for each year. For example, in $1987 \$ 1$ in 1972 was worth $\$ 2.72$. For this year the multiplier used to convert nominal to present 2021 values was calculated as $\$ 6.62 / \$ 2.72=2.4338$. These multipliers ranged from 1.00 for 2021 to 6.62 in 1972 .

\section{$\underline{\text { References: }}$}

Adcock, K., Emslie, R. (1994). The role of trophy hunting in white rhino conservation, with special reference to Bop Parks, in: Penzhorn, B.L., Kriek, N.P.J. (Eds.), Proceedings of a Symposium on "Rhinos as Game Ranch Animals", Onderstepoort, 9 \& 10 September 1994. Presented at Rhinos as Game Ranch Animals, South African Veterinary Association, Onderstepoort, South Africa, pp. 35-41. ISBN 1-875088-17-2

Buys D. (1987). A summary of the introduction of white rhino onto private land in the Republic of South Africa: Report for Rhino and Elephant Foundation. http://www.rhinoresourcecenter.com/pdf files/129/1291956323.pdf

Emslie, R. H., Milliken, T., Talukdar, B., Adcock, K., \& Knight, M. H. (2019). African and Asian rhinoceroses-Status, conservation and trade: A report from the IUCN Species Survival Commission (IUCN/SSC) African and Asian Rhino Specialist Groups and TRAFFIC to the CITES Secretariat pursuant to Resolution Conf. 9.14 (Rev. CoP17), CoP18 Doc. 83.1 Annex 2. CITES Secretariat. Hall-Martin, A., du Toit, J. G., Hitchens, P. M., \& Knight, M. H. (2009). An exert of the 2008 survey of white rhinoceros, Ceratotherium simum simum, on private land in South Africa: Report to WWF-African Rhino Programme. WWF South Africa. Retrieved 9 October 2021, from http://www.rhinoresourcecenter.com/pdf_files/146/1465289401.pdf

Milliken, T., \& Shaw, J. (2012). The South Africa-Viet Nam Rhino Horn Trade Nexus: A Deadly Combination of Institutional Lapses, Corrupt Wildlife Industry Professionals and Asian Crime Syndicates. http://www.traffic.org/species- reports/traffic species mammals66.pdf.

\section{Comparative African data}

We were informed that there had been a small number of white rhino hunts in Zimbabwe on private land. A comparative tabulation report from the CITES database suggests that a very small number of hunts and trophy exports (at least two, maximum seven) took place from 1998. Given this uncertainty and as so few white rhinos and no black rhinos have been legally hunted in Zimbabwe, this study has focused on the two countries that hunted significant numbers of both species of rhino (South Africa and Namibia). Figures 4 and 5 however do present trends in estimated rhino numbers over time in Zimbabwe.

For many years the majority of African rhinos have been conserved by four countries-South Africa, Namibia, Zimbabwe, and Kenya. For this reason, Figures 4 and 5 provide a breakdown of numbers for these four countries, with the remainder summed and included as Rest of Africa totals.

\footnotetext{
${ }^{4}$ Downloaded from https://www.officialdata.org/us/inflation/1972?amount=1 on the 9th December 2021.
} 


\section{Poaching data}

Since 2006 the AfRSG has regularly compiled and updated reported poaching data based on information kindly supplied by range states. Poaching updates are also published in AfRSG Chair reports in the journal Pachyderm - see Knight (2020) - and in joint IUCN/TRAFFIC rhino reports to CITES CoP's (e.g., Emslie et al. 2019).

Reported poaching figures represent minimum numbers, because in some populations (especially in very large areas with lower field ranger densities) as many as $20 \%$ of carcasses may be undetected.

\section{References:}

Emslie, R. H., Milliken, T., Talukdar, B., Adcock, K., \& Knight, M. H. (2019). African and Asian rhinoceroses-Status, conservation and trade: A report from the IUCN Species Survival Commission (IUCN/SSC) African and Asian Rhino Specialist Groups and TRAFFIC to the CITES Secretariat pursuant to Resolution Conf. 9.14 (Rev. CoP17), CoP18 Doc. 83.1 Annex 2. CITES Secretariat.

Knight, M. (2020). African Rhino Specialist Group report / Rapport du Groupe de Spécialistes du Rhinocéros d'Afrique. Pachyderm, 61, 23-42.

https://pachydermjournal.org/index.php/pachyderm/article/view/67 